\title{
The effect of severe plastic deformation on the IF steel properties, evolution of structure and crystallographic texture after dual rolls equal channel extrusion deformation
}

\author{
M. B. Jabłońska ${ }^{1}$ (D) K. Kowalczyk ${ }^{2} \cdot$ M. Tkocz ${ }^{1} \cdot$ R. Chulist $^{3} \cdot$ K. Rodak ${ }^{1} \cdot$ I. Bednarczyk ${ }^{1} \cdot$ A. Cichański ${ }^{4}$
}

Received: 2 August 2021 / Revised: 31 August 2021 / Accepted: 1 September 2021 / Published online: 22 September 2021

(C) The Author(s) 2021

\begin{abstract}
This paper presents some results of the influence of severe plastic deformation on the microstructure evolution, grain refinement aspect, and mechanical properties of ultra-low carbon steel. Ti-stabilized experimental IF steel was deformed at a room temperature with unconventional SPD process-dual rolls equal channel extrusion (DRECE). Mechanical properties and structure of ferritic steel in initial state and after selected steps of deformation were investigated. The mechanical properties were determined by static tensile tests carried out at a room temperature and microhardness research. The structural investigations involved using scanning transmission electron microscopy observations, electron back scattered diffraction and measurements of the crystallographic texture. The DRECE process affects the evolution of the structure. The microstructural investigations revealed that the processed strips exhibited a dislocation cell and grain structures with mostly low angle grain boundaries. The electron backscattering diffraction (EBSD) examination showed that the processed microstructure is homogeneous along the strips thickness. The mechanical properties of the DRECE-processed IF steel strips increased with an increase the number of passes.
\end{abstract}

Keywords SPD process $\cdot$ Ultra-low carbon steel $\cdot$ Microstructure $\cdot$ Crystallographic texture

\section{Introduction}

Automotive industry extensively uses ultra-low carbon steel sheet for the fabrication less important parts of the car body. One of them is interstitial free steels due to the fact it is suitable for the forming operations because of its excellent formability and high planar isotropy [1]. IF ultralow-carbon steels are characterized by a single-phase ferritic microstructure with decreased amount of interstitial carbon and

M. B. Jabłońska

magdalenabarbara.jablonskapriv@gmail.com

1 Faculty of Materials Engineering, Silesian University of Technology, Krasińskiego 8, 40-019 Katowice, Poland

2 Faculty of Mechanical Engineering, Wroclaw University of Technology, Ignacego Łukasiewicza 5, 50-371 Wrocław, Poland

3 Institute of Metallurgy and Materials Science of Polish Academy of Sciences, Reymonta 25, 30-059 Kraków, Poland

4 UTP University of Science and Technology, Al. prof. S. Kaliskiego 7, 85-796 Bydgoszcz, Poland nitrogen in the ferrite, which is achieved by micro-alloying elements of $\mathrm{Ti}$ and/or $\mathrm{Nb}$ and formation of small volume fractions of carbides and nitrides [1,2]. Due to the decrease in the solid solution hardening effect of interstitial atoms, IF steels showed a low strength. These features limit its broader applications in conditions where high strength is needed in addition to high formability. Enhancing the strength with adequate ductility may increase the potential applications of interstitial free steel in new applications $[3,4]$. The increasing requirements, which materials need to meet, have enforced improvement of manufacturing processes to obtain high mechanical properties [5, 6]. Recently, the grain refinement of metallic materials has been investigated intensively. There are two basic methods, i.e., thermomechanical processing $[7,8]$ and severe plastic deformation [9-11] to refine grain sizes of bulk steels for the ultrafine or submicron range. As is known, one of the most successful processes to increase mechanical properties without dramatically decreasing plasticity is based on severe plastic deformation-SPD [9-12]. Studies presented by O. Saray and N. Tsuji [12-14] confirm that it is possible to obtain highstrength properties through fragmentation of the structure 
in low carbon ferritic IF steels shaped with SPD methods, i.e., equal channel angular sheet extrusion (ECASE) [12] and accumulative roll bonding (ARB) [13-15]. Tsuji et al. [13] indicate that the ARB process creates ultrafine grains in the IF steel processed up to a strain of 4.0 at $773 \mathrm{~K}$ and the grains are surrounded by high-angle grain boundaries. T Kim [16] got a high-tensile strength above $800 \mathrm{MPa}$ and a tensile elongation over 155 achieved with both ECAP routes was regarded as a good combination of strength and ductility by grains refinement. For example, structural analysis in work of O. Saray [12] showed that in a result of a severe plastic deformation with ECAP grains were divided into smaller volumes, however, the increase of the deformation did not result in obtaining a large fraction of ultrafine grain boundaries with high-angle boundaries (HAGBs), and strain hardening of the material is attributed to relatively high density of dislocations and the presence of dislocation boundaries which are geometrically necessary boundaries (GNBs) and incidental dislocation boundaries IDBs. The detailed evolution of microstructure and identification the mechanism of grain refinement in the interstitial free steel during plastic deformation by SPD methods is an issue which is not yet completely understood [17-19].

Despite the use of the conventional SPD methods to deform low carbon steels in the last few years there were steps taken to improve these methods. Hybrid SPD methods can significantly influence on the increase the degree of microstructure fragmentation and affect the nature of forming grain boundaries. Unconventional and hybrid SPD methods allow to deform materials of much more dimensions than the ones that are used in classical method, and they increase the homogeneity of the obtained structure [20,21].

One of the very promising hybrid SPD methods for processing of micro-alloyed low carbon steel is dual rolls equal channel extrusion (DRECE) [22, 23]. The DRECE method uses the principle of reproducible plastic forming to fragment the structure and improve strength properties of steel strip. The material in the form of a sheet or strip is introduced into the working space by means of the main roll $\mathrm{D}$ and the supporting rolls $\mathrm{d}$, and then pressed through the shaping tool with the given $\alpha$ angle. The upper support and the upper die ensure the correct movement of the strip between the rollers during the process. The shaping process is based on the extrusion technology with zero reduction of strip's thickness while achieving a high degree of deformation in the material being formed. [23-25]. Multiple plastic deformations carried out this way determine the change of the structure and mechanical properties in relation to the initial material.

In the present study, the dual rolls equal channel extrusion method was applied to the ultralow-carbon steel IF to study the microstructural evolution taking into account the grain refinement mechanism, crystallographic texture and mechanical properties after selected DRECE passes. The identification of structure changes of IF steel carried out in this work using the scanning transmission electron microscopy STEM and electron backscattering diffraction EBSD is supplements the current state of knowledge in the field of the plastic deformation of interstitial free steel with the unconventional DRECE method.

\section{Materials and experimental methods}

\subsection{Materials and processing parameters}

Ti-stabilized experimental IF steel with the chemical composition of 0.004 wt. \% C, 0.016 wt. \% Si, 0.21 wt.\% Mn, 0.013 wt.\% Ti, 0.0026 wt.\% $\mathrm{Al}$ and balance $\mathrm{Fe}$, has been used in this study. The testing material had a form of $800-\mathrm{mm}$ long, 60-mm-wide and 2-mm-thick strips. The steel strips were subjected to plastic deformation at room temperature by the DRECE method (Fig. 1) with the die angle $\alpha=108^{\circ}$. DRECE method (Dual Rolls Equal Channel Extrusion) is the new prototype proprietary SPD method for deformation metal strips. It has been developed in the Department of Mechanical Technology at VSB-Technical University of Ostrava by team of Professor S. Rusz. This device is unique in Europe, since the process of structure refining in flat blanks is ate present still under development. The DRECE method is similar to the Dissimilar Channel Angular Pressing process (DCAP). The equipment consists of the following main parts: a main roll, supporting tool, a feed roll, a forming tools (upper die, lower die) and upper die support as well as lower die support. A strip is fed into the working space between main roll and red feed roll and it is pushed by the blue feed roll with the help of pressure rollers through the forming tools without a change of its cross-section [23].

\subsection{Mechanical testing and microstructural examination}

The hardness of strips was measured with Vickers hardness tester type of ZWICK Roel ZHU at load of $1 \mathrm{~N}$ were conducted on the polished longitudinal sections. Work hardening characteristics were obtained during static tensile tests of a series three samples with a rectangular cross-section at room $\left(20^{\circ} \mathrm{C}\right)$ temperature using ZWICK testing machine with a maximal force of $250 \mathrm{kN}$. The nominal strain rate of $10^{-3} \mathrm{~s} 1$ was applied. The tensile tests were performed in accordance with the requirements of the ASTM standard [26].

Samples for the study of mechanical properties and microstructure analysis were collected in accordance with Fig. 2. 
Fig. 1 Scheme of DRECE method

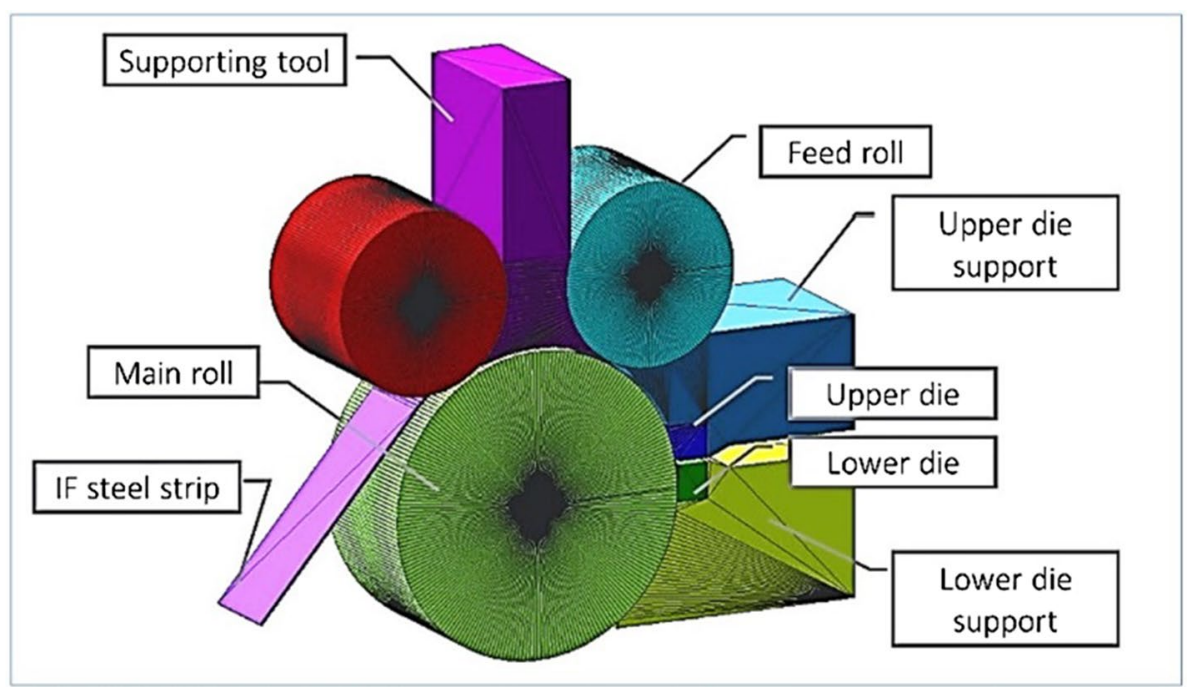

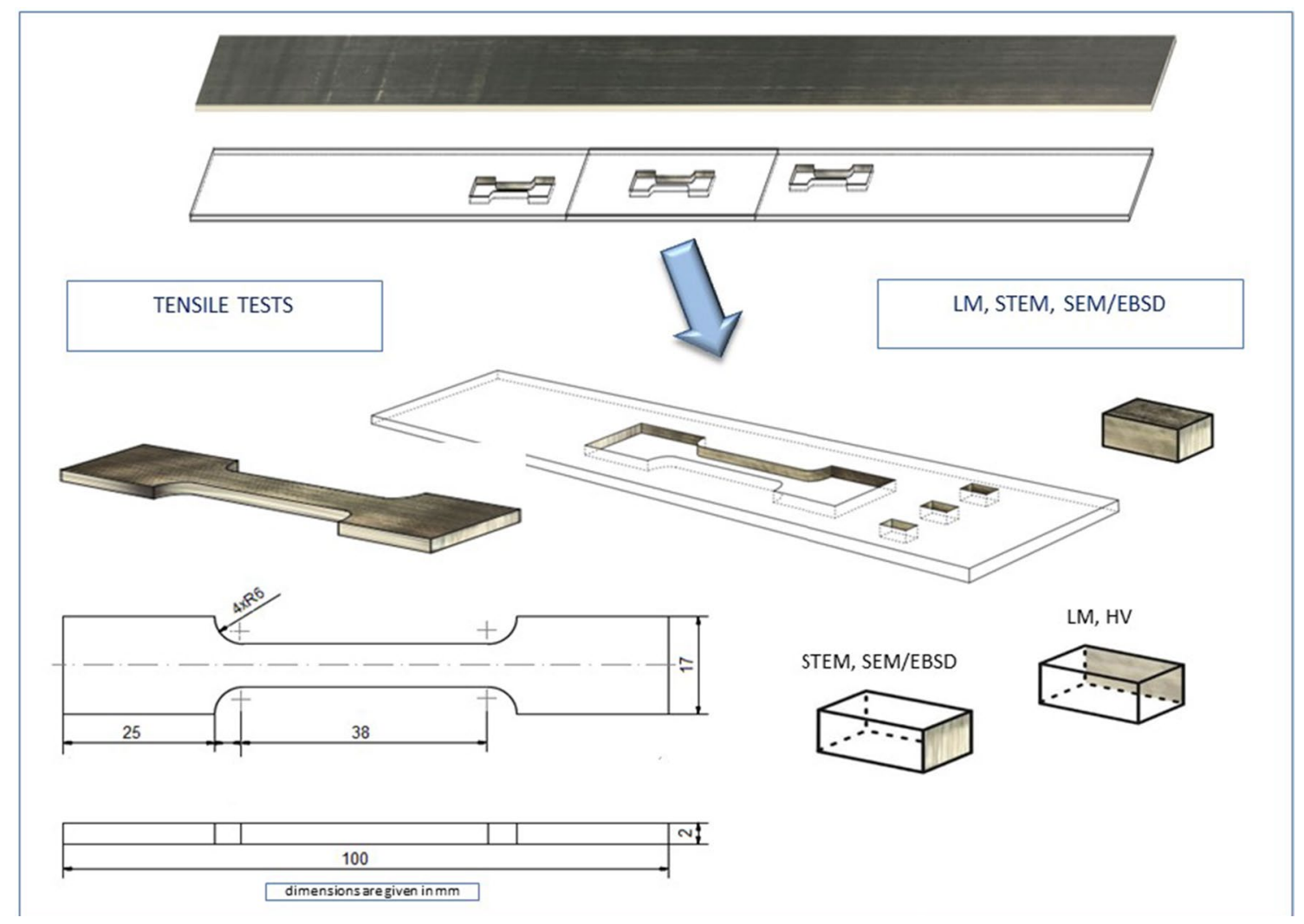

Fig. 2 Scheme of sampling for mechanical testing and microstructure analysis

Detailed studies of the microstructure IF steel before and after the DRECE process were carried out using the scanning transmission electron microscopy STEM of the type HITACHI HD-2300A equipped with a FEG gun with a Schotky emitter. The microscope works at an accelerating voltage of $200 \mathrm{kV}$. The STEM observation were made on the longitudinal section and the research was conducted in the bright field. The specimens for STEM examination were samples with a thickness of approx. $1 \mathrm{~mm}$. The initial thinning was carried out on mechanical grinders to a thickness of approx. $0.08 \div 0.03 \mathrm{~mm}$. Discs with a diameter of $3 \mathrm{~mm}$ were then cut using a die. The samples prepared in this way were thinned using the method of twin jet electrolytic polishing with $43 \mathrm{~V}$ voltage. 
The disorientation angles between neighboring grains were measured using the FEI Quanta 3D scanning electron microscope (SEM) equipped with a cold field emission gun and an electron back scattering diffraction detector (EBSD) at a beam voltage of $20 \mathrm{kV}$ EHT with a measuring step of 100-200 nm. Data acquisition in the form of maps of the crystallographic orientation of structure components was performed with the EDAX/ TSL system. EBSD maps are shown with an IPF color coding with respect to the transverse direction of the sample. Pole Figs. (111), (200), (220) and the orientation distribution function (ODF) were also exported to compare the crystallographic texture. Based on the SEM / EBSD results obtained, the mean particle diameter was determined. The grains lying on the periphery of the image were not taken into account in these measurements. Additionally, the distributions of grain sizes and angles of disorientation were determined and the grain shape index was determined.

\section{Results}

\subsection{Mechanical properties after severe plastic deformation}

The dual rolls equal channel extrusion process has a positive effect on the increase in the strength properties of the investigated steel. Figure 3 shows characteristics of the mechanical properties: the ultimate tensile strength TS, the yield stress YS and the HV 0,1 hardness for the investigated ferritic steel for the initial sample as well as for samples after 3, 5 and 7 passes of the DRECE process. The elongation \%EL. as a function of number of DRECE cycle is shown in Fig. 2. It is seen that effective hardening effect is observed after three passes. The tensile strength of IF steel increases after the third pass for the initial state from 263 to $315 \mathrm{MPa}$. The yield stress for the initial sample was $123 \mathrm{MPa}$. It increased

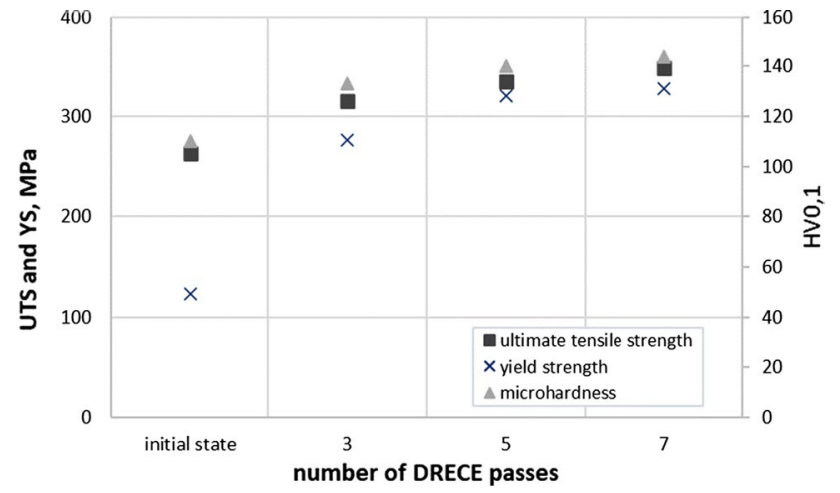

Fig.3 Mechanical properties of the investigated steel in the initial state and after selected DRECE passes

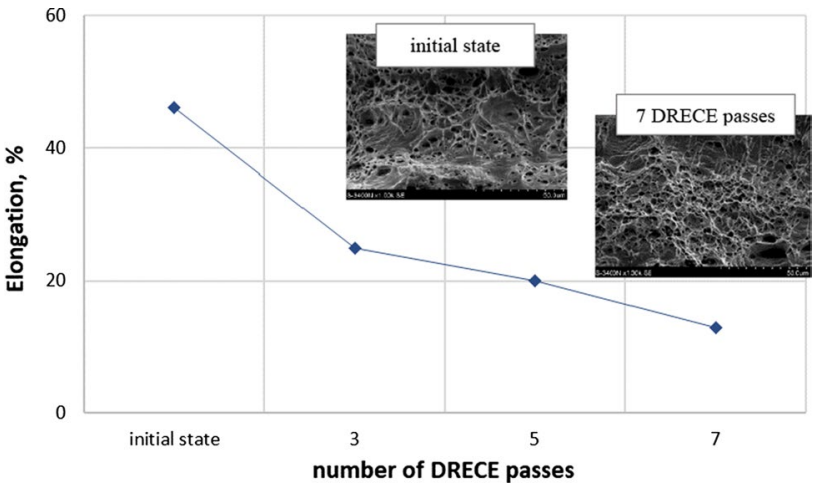

Fig.4 Influence of DRECE process on the elongation of IF steel and the surfaces of fractures of steel in the initial sample and after 7 DRECE passes

up to $276 \mathrm{MPa}, 321 \mathrm{MPa}$ and $328 \mathrm{MPa}$ for 3 passes, 5 passes and 7 passes, respectively, which correlates very with the evolution of hardness. In the initial state the investigated steel exhibits very good plastic properties; however, as the number of passes increases, there is a significant decrease in the ductility. The percent elongation drops systematically from $46 \%$ for the sample in the initial state to $13 \%$ for the sample after last 7 th pass. The decrease in the elongation value is typical for most materials processed with SPD methods [12, 16-18, 27-29]. Regardless of this condition, the sample after the 7 DRECE passes is characterized by a ductile fracture with characteristic small parabolic dimples. There are areas with inhomogeneous holes distribution and varied sizes of dimples (Fig. 4).

\subsection{Microstructure evolution and texture in the investigated steel}

STEM examinations show that application of deformation results in changes related to evolution of the initial

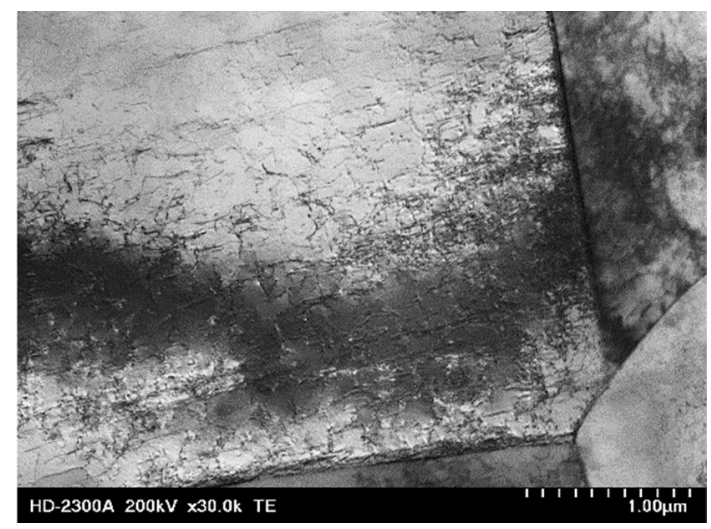

Fig. 5 STEM photographs of the IF steel microstructure at the initial state 

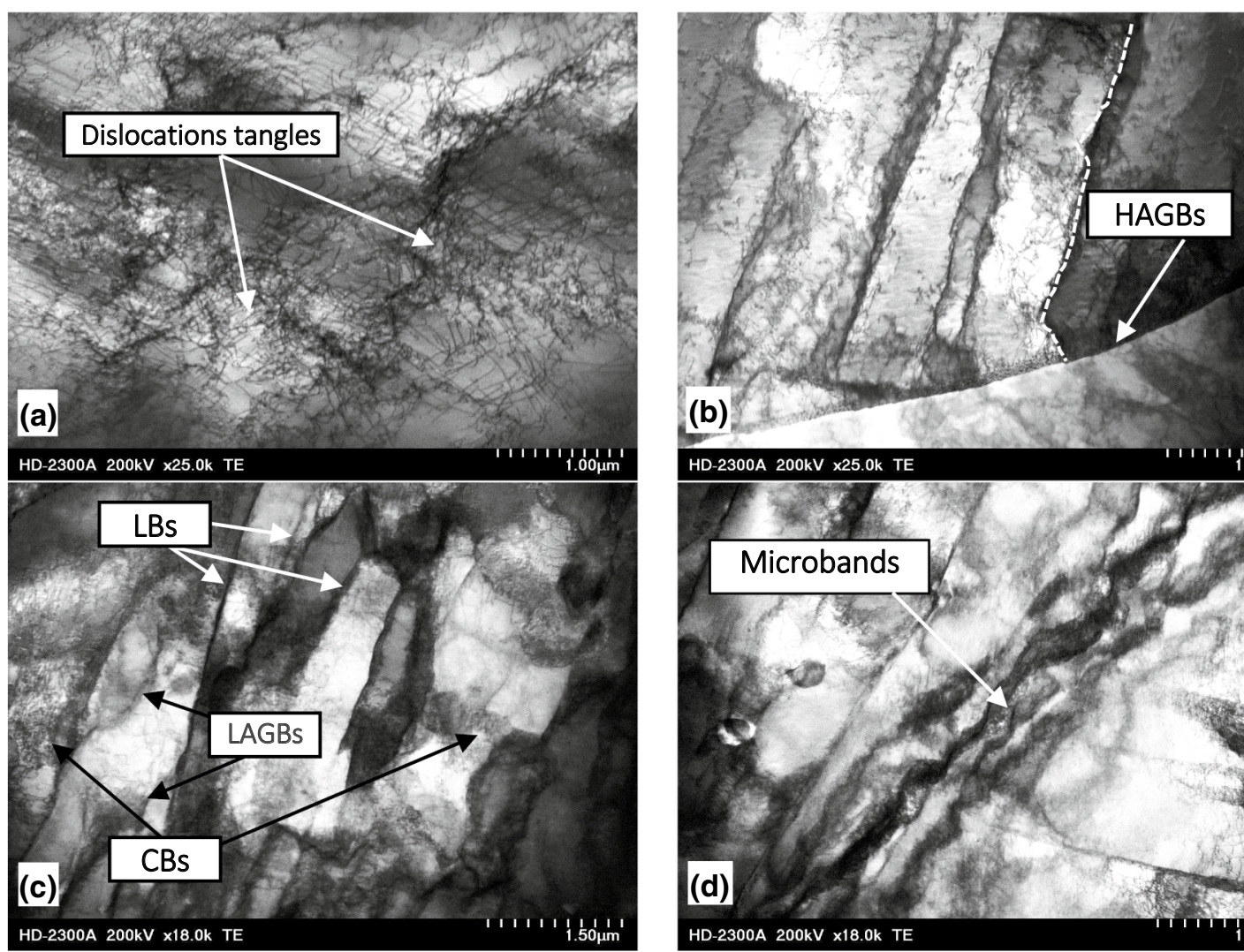

(b)
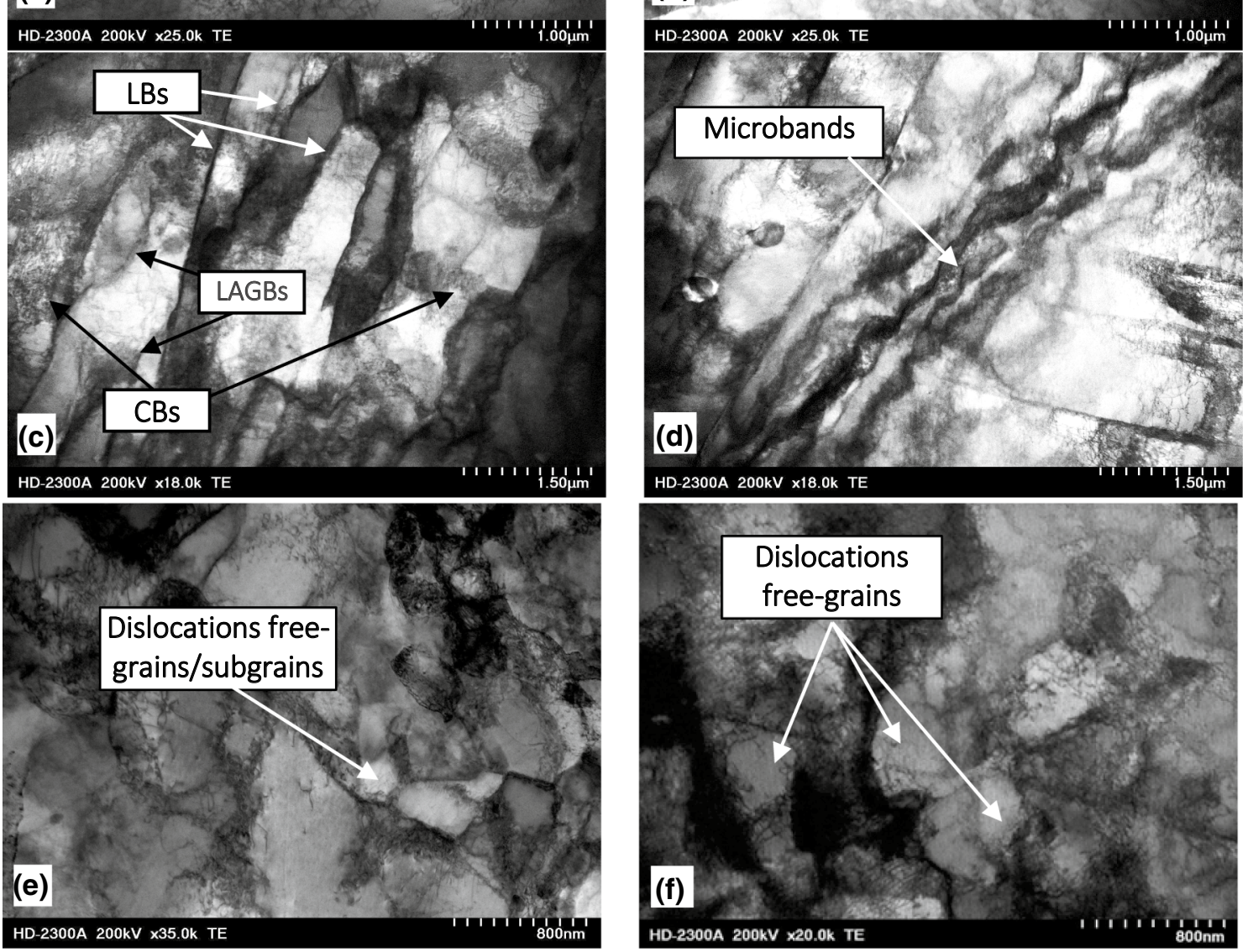

Fig. 6 STEM photographs of the IF steel microstructure after: 2 DRECE passes (a), 3 DRECE passes (b), 4 DRECE passes (c), 5 DRECE passes (d), 6 DRECE passes (e), 7 DRECE passes (f)

microstructure (Fig. 5) of interstitial free steel, which consist a grains with dislocations visible as several and low tangled.

Figure $6 \mathrm{a}-\mathrm{f}$ shows a microstructure from 2 nd to the 7 th DRECE passes. After the second passes an increase of the density of dislocation inside the grains and the occurrence of numerous dislocation tangles are visible (Fig. 6a). Also, primary high-angle boundaries (HAGBs) are visible. After 3 DRECE passes the dislocations form cellular structures. In the microstructure the phenomenon of grain boundary distortion is observed. Similar results were also observed by Sun et al. [27]. This phenomenon of creating a clear steps on the grain boundary line can be a result of shear microbands (Fig. 6b). After the further DRECE cycles there are areas where accumulation and rearrangement of dislocations intensify, which lead to the formation of low-energy systems with LAGBs boundaries. Lamellar LBs boundaries are formed and within them single dislocations can be identified (Fig. 6c). In the microstructure the dislocation cells blocks CBs are also visible as the blocked areas (Fig. 6c). The formation of LAGBs boundaries as a result of the reconstruction of dislocation boundaries is a very important stage for materials deformed with SPD methods, they will evolve into 


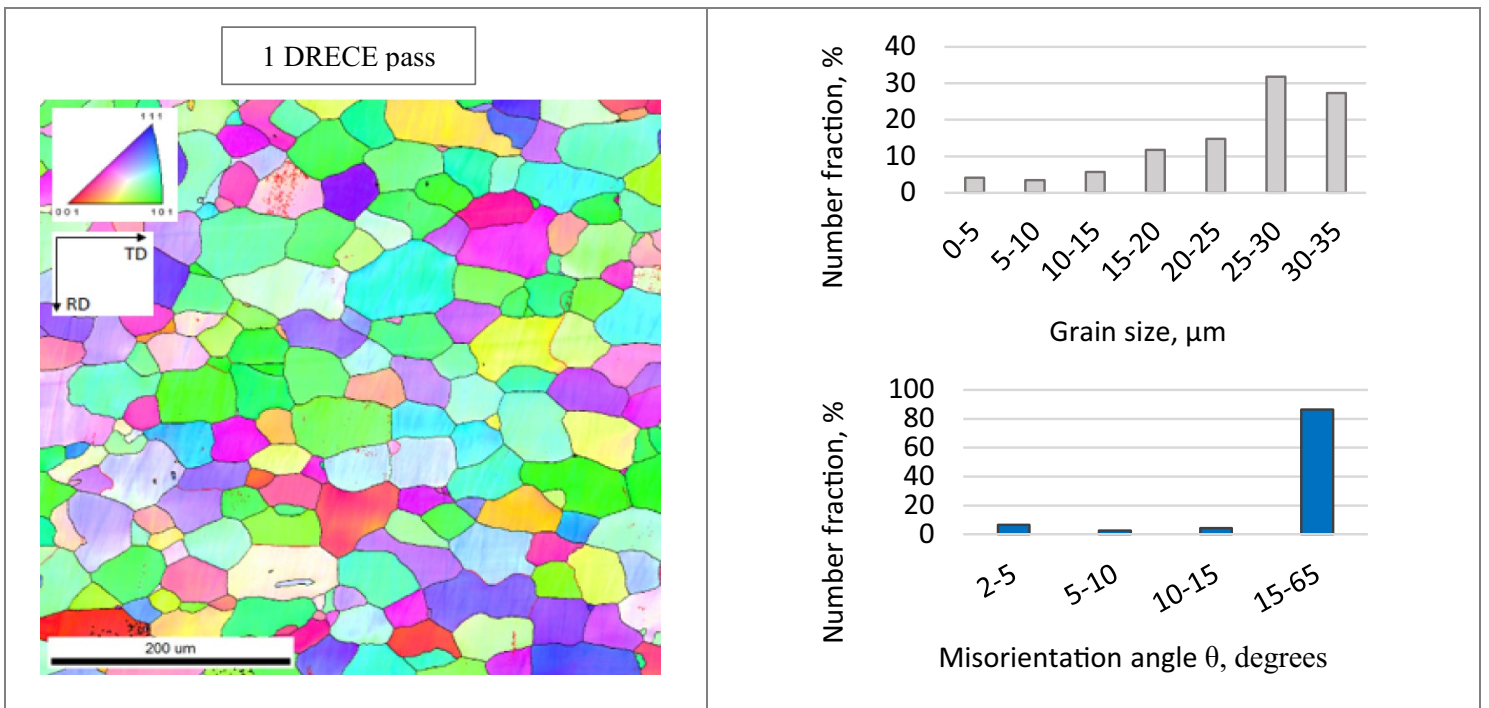

Fig. 7 Results of EBSD analysis for IF steel after the 1 DRECE pass. The size and shape of grains map (HAGBs marked black, LAGBs marked red, distribution of grain size and the fraction of misorientation angles

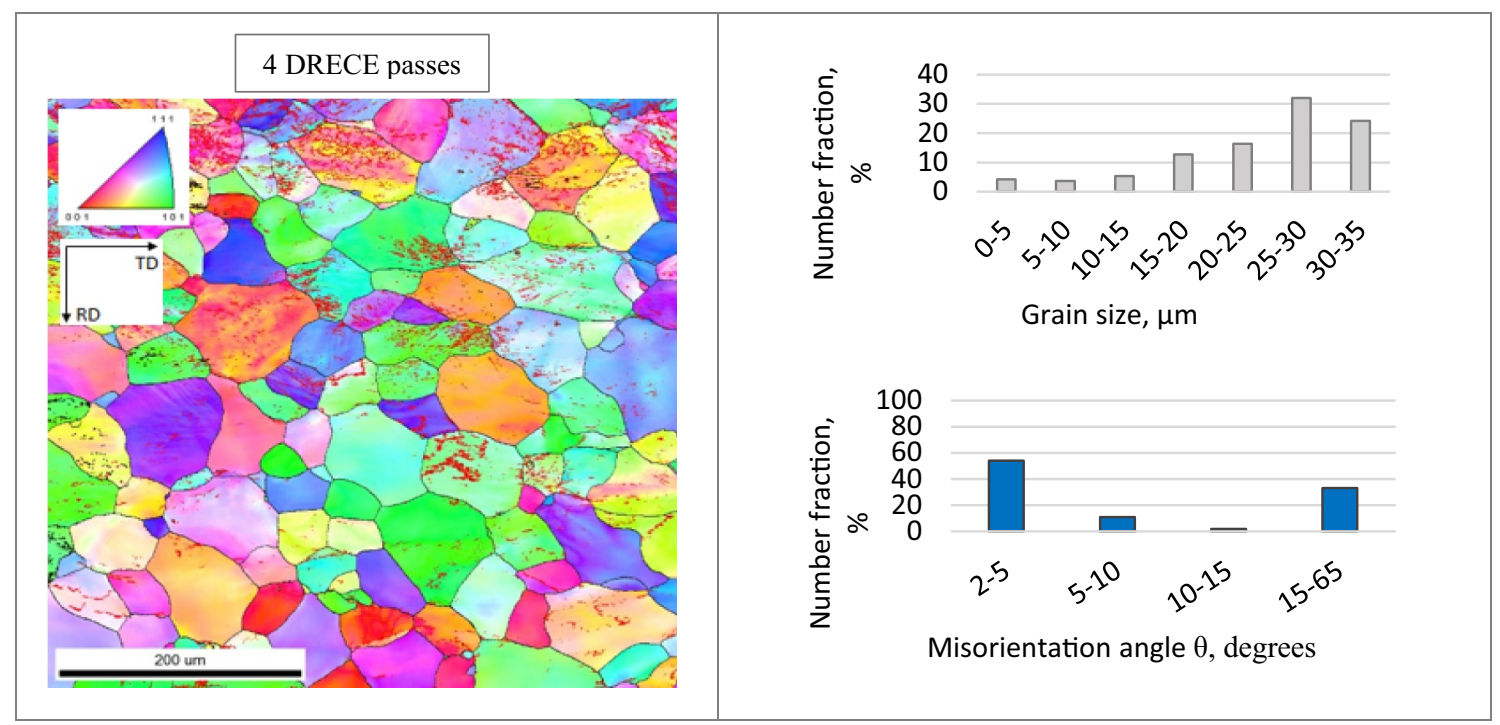

Fig.8 Results of EBSD analysis for IF steel after the 3 DRECE pass. The size and shape of grains map (HAGBs marked black, LAGBs marked red, distribution of grain size and the fraction of misorientation angles

the form of homogeneous grains with wide-angle boundaries with the increase of deformation. After 6 passes, the dislocation cells are partially replaced by finer and well-defined regular grains. The dislocation-free grains appear (Fig. 6e, f). After 7 passes DRECE clearly shows that the dislocation density is lower inside sub-grains, and most of them are accumulated and entangled with others around the boundaries of the grain (Fig. 6f).
Figures 7, 8, 9 show the EBSD evolution of microstructure maps of the IF steel strips after selected DRECE passes, respectively. Distribution of the grain size (mean equivalent diameter) was determined for grains $\leq 35 \mu \mathrm{m}$. The grain size value in the initial state and after subsequent DRECE passes were determined based on the complete statistics of grain sizes. After the $1 \times$ pass (Fig. 7) the grain size is approx. $35 \mu \mathrm{m}$. The fraction of HAGBs is high and amounts 


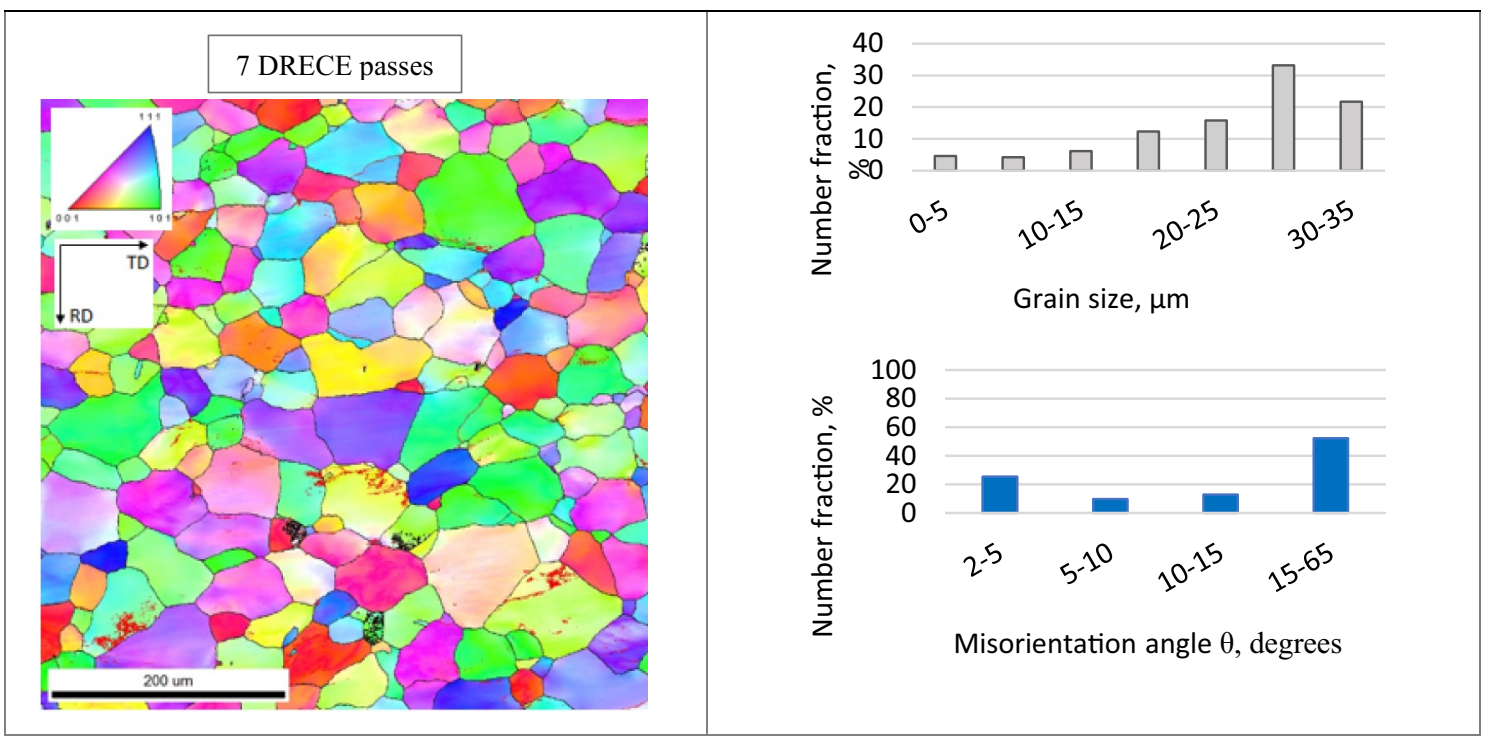

Fig.9 Results of EBSD analysis for IF steel after the 7 DRECE pass. The size and shape of grains map (HAGBs marked black, LAGBs marked red, distribution of grain size and the fraction of misorientation angles

to over $89 \%$ (mainly the primary grains boundaries). After the $4 \times$ pass (Fig. 8) the significant increase of low angle fraction is observed. The fraction of LAGBs in the range of $2-5^{\circ}$ is $54 \%$. The grain size reduces slightly with the increase of deformation, however, for further passes there is a tendency to change the grain size towards lower values. The area faction of grains with mean equivalent diameter of $30-35 \mu \mathrm{m}$ for the sample after $1 \times$ pass is $27 \%$, and after the 7 pass (Fig. 9) it is $21 \%$. The share of the grain fraction in the range of $10-15 \mu \mathrm{m}$ in individual passes increases, while the grain fraction below $5 \mu \mathrm{m}$ for states after the $1 \times, 4 \times$, and $7 \times$ pass does not change significantly and remains at the level of $4-4.5 \%$.

In order to follow the evolution of the structure after the subsequent DRECE passes the obtained pole figures and orientation distribution function (ODF) were analyzed. Figure 10a shows the reference figure and ODF, and also pole figures for the IF steel after the deformation with DRECE (Fig. 10b-e). In the experimental steel in the initial state the so-called fibrous texture (111) is not identified. Only local maximums with higher intensities are visible for orientation groups along the $\alpha$ fiber. Crystallographic structure does not change significantly during subsequent DRECE passes. The changes apply only to a slight weakening of the texture after $7 \times$ pass (Fig. 10e). As suggest Tsui et al. [13] the texture effect might be one of the keys to understand the formation mechanism of the ultrafine grains in ARB, in other words, the ultrafine grain subdivision.

\section{Conclusion}

The main findings and conclusions of this study can be summarized as follows:

1. The experimental IF steel was successfully processed in the continuous deformation using the dual rolls equal channel extrusion method up to 7 passes at a room temperature.

2. After 4 DRECE passes, fraction of low angle boundaries LAGBs increases significantly from $7 \%$ for the initial sample to $54 \%$. The mechanism of IF steel grain refinement after the DRECE process may be based on the microstructural evolution understood as dislocation accumulation, transformation of dislocation boundaries into low-angle boundaries and the intersection of the microbands identified in the microstructure.

3. The conducted research showed that to obtain the fragmentation of the structure assessed on the basis of the grain size, it is necessary to take into account the change of deformation parameters, which will intensify the progress of the microstructure evolution and, consequently, will lead to obtain a larger fraction of ultra-metric grains in the tested steels.

4. The deformation with the DRECE method has little effect on the crystallographic texture of the low carbon IF steel. This texture does not change significantly during subsequent DRECE passes. The changes apply only to a slight weakening of the texture after the last pass. 


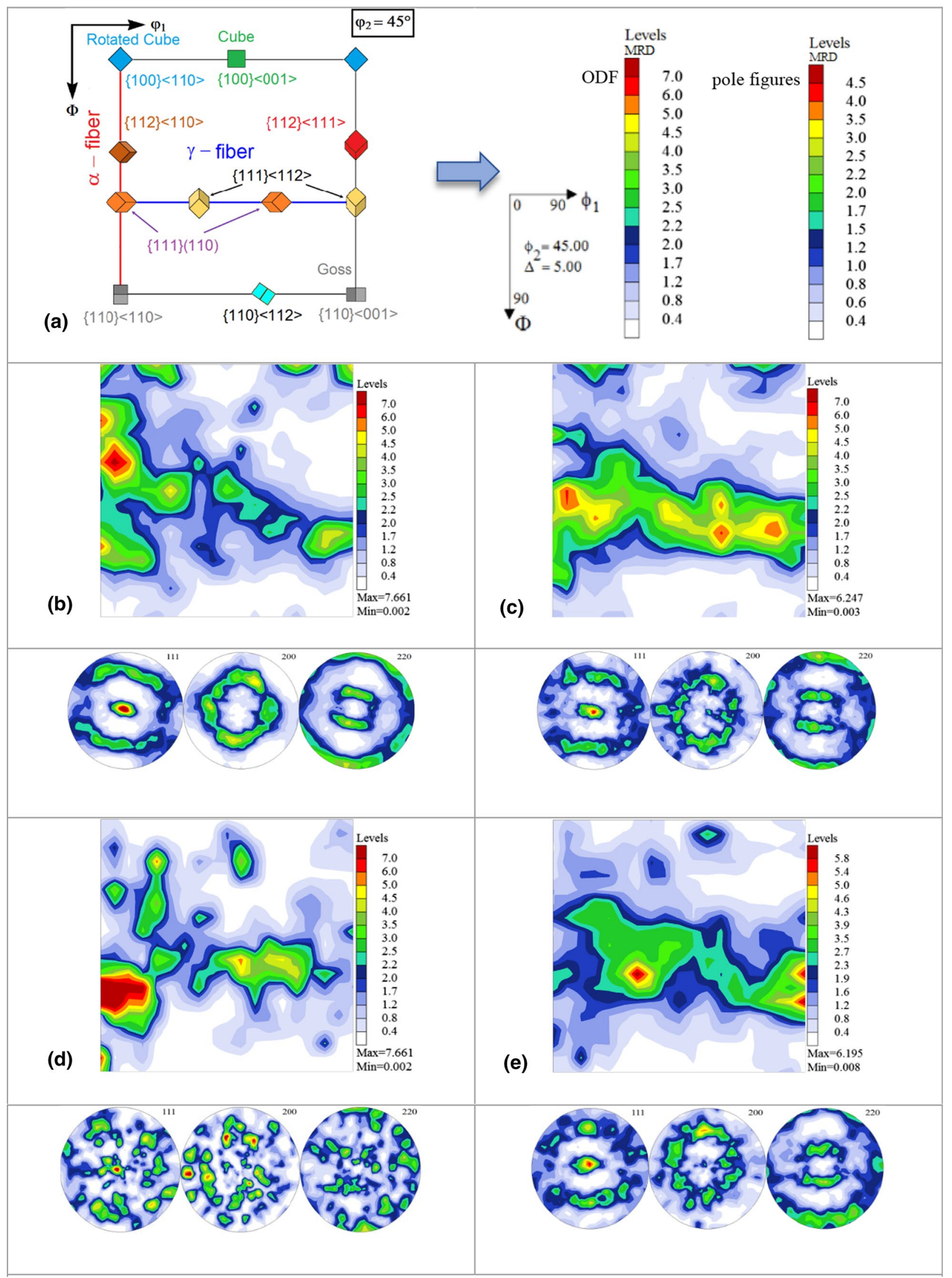


४Fig.10 Key figure for section $\varphi_{2}=45^{\circ}$ (a) [26], pole Figures (111), (200) and (220) for the IF steel along with ODF section $\varphi_{2}=45^{\circ}$ (a) for the initial sample (b) and samples deformed by DRECE after 1 pass (c), 4 passes (d) and 7 passes (e)

5. The mechanical properties of the DRECE-processed IF steel strips increased with an increase in the number of passes and finally the yield strength reached a maximum of $328 \mathrm{MPa}$ after 7 DRECE passes, which are more than two times higher as compared to that of the as-received material.

6. The elongation to failure considerably decreased with the number of passes. After 7 DRECE passes, it decreased down to $13 \%$ from $46 \%$ in the as-received condition. The increase in strength after the DRECE was attributed to the deformation microstructure including refined grains with relatively high density of dislocations.

7. After DRECE deformation, ductile fracture of IF steels was confirmed by fractographic investigations.

Funding K. Kowalczyk acknowledges the financial support of the National Science Center, Poland (Grant No. 2018/31/N/ST8/03134) and the Ministry of Science and Higher Education, Poland.

Data availability The data that support the findings of this study are available from the corresponding author upon reasonable request.

\section{Declarations}

Conflict of interest The authors declare that they have no conflict of interest.

Open Access This article is licensed under a Creative Commons Attribution 4.0 International License, which permits use, sharing, adaptation, distribution and reproduction in any medium or format, as long as you give appropriate credit to the original author(s) and the source, provide a link to the Creative Commons licence, and indicate if changes were made. The images or other third party material in this article are included in the article's Creative Commons licence, unless indicated otherwise in a credit line to the material. If material is not included in the article's Creative Commons licence and your intended use is not permitted by statutory regulation or exceeds the permitted use, you will need to obtain permission directly from the copyright holder. To view a copy of this licence, visit http://creativecommons.org/licenses/by/4.0/.

\section{References}

1. Narayanasamy R, Sathiya Narayanan C. Forming, fracture and wrinkling limit diagram for if steel sheets of different thickness. Mater Des. 2008;7:1467-75.

2. Jin YH, Huh MY, Chung YH. Evolution of texture and microstructure in IF-steel sheets during continuous confined strip shearing and subsequent recrystallization annealing. J Mater Sci. 2004;39:5311-4.
3. Tjong SC, Chen H. Nanocrystalline materials and coatings. Mater Sci Eng A. 2004;45:1-88.

4. Valiev R, Krasilnikov NA, Tsenev NK. Plastic deformation of alloys with submicrongrained structure. Mater Sci Eng A. 1991;137:35-40.

5. Song R, Ponge D, Raabe D, Speer JG, et al. Overview of processing, microstructural and mechanical properties of ultrafinegrained bbc steels. Mater Sci Eng, A. 2006;441:1-17.

6. Takaki S, Kawasaki K, Kimura Y. Mechanical properties of ultra fine grained steel. J Mater Process Technol. 2001;117:359-71.

7. Belyakov A, Sakai T, Miura H, Kaibyshev R. Strain-induced submicrocrystalline grains developed in austenitic stainless steel under severe warm deformation. Philos Mag Lett. 2000;80:711-8.

8. Hickson MR, Hodgson PD. Effect of preroll quenching and post-roll quenching on production and properties of ultrafine ferrite in steel. Mater Sci Technol. 1999;15:85-90.

9. Han B, Yue S. Processing of ultrafine ferrite steels. J Mater Process Technol. 2003;136:100-4.

10. Alexander DJ. New methods for severe plastic deformation processing. J Mater Eng Perform. 2007;16:360-74.

11. Jamaati R, Toroghinejad M. Fabrication of nano/ultra-fine grained IF steel via SPD processes: a review. Trans Indian Inst Met. 2014;67:787-802.

12. Saraya O, Purceka G, Karamanb I, et al. Equal-channel angular sheet extrusion of interstitial-free (IF) steel: microstructural evolution and mechanical properties. Mater Sci Eng, A. 2011;528:6573-83.

13. Tsuji N, Ueji R, Minamino Y. Nonoscale crystallographic analysis of ultrafine grained IF steel fabricated by ARB process. Scripta Mater. 2002;47:69-76.

14. Kamikawa N, Sakai T, Tsuji N. Effect of redundant shear strain on microstructure and texture evolution during accumulative rollbonding in ultralow carbon IF steel. Acta Mater. 2007;55:5873-88.

15. Costa A, Reis A, Kestens L, Andrade M. Ultra grain refinement and hardening of IF-steel during cumulative roll-bonding. Mater Sci Eng, A. 2005;406:279-85.

16. Kim HS, Ryu WS, Janeček M, Baik SC, Estrin Y. Effect of equal channel angular pressing on microstructure and mechanical properties of IF steel. Adv Eng Mater. 2005;7:43-6.

17. Mathis K, Krajnak T, Kuzel R, et al. Structure and mechanical behavior of interstitial free steel processes by equal channel angular pressing. J Alloy Compd. 2011;509:3522-5.

18. Sujoy S, Hazra E, Pereloma A. Microstructure and mechanical properties after annealing of equal-channel angular pressed interstitialfree steel. Acta Mater. 2011;59:4015-29.

19. Eddahbi M, Rauch EF. Texture and microstructure of ultra-low carbon steel processed by equal channel angular extrusion. Mater Sci Eng, A. 2009;502:13-24.

20. Wongsa-Ngam J, Wen H, Langdon TG. Microstructural evolution in a Cu-Zr alloy processes by a combination of ECAP and HPT. Mater Sci Eng A. 2012;579:105-15.

21. Lugo N, Lorca N, Cabrera JM, Horita Z. Microstructures and mechanical properties of pure copper deformed severely by ECAP pressing and high pressure torsion. Mater Sci Eng A. 2018;477:366-71.

22. Rusz S, Kłyszewski A, Salajka M, Hilser O, Cizek L, Klos M. Possibilities of application methods DRECE in forming of non-ferrous metals. Arch Metall Mater. 2015;60:3011-6.

23. Rusz S, Cizek L, Michenka V et al. New type of device for achievement of grain refinement in metal strip, COMAT 2014, 19-21.11.2014 r. Pilsen, Czech Republic EU. 2014.

24. Kowalczyk K, Jabłońska M, Rusz S, et al. Influence of the DRECE proces of severe plastic deformation on the mechanical properties of the ultra-low carbon interstitial free steel. Arch Metall Mater. 2018;63:2095-100. 
25. Jabłońska MB, Kowalczyk K, Tkocz M, et al. Dual rolls equal channel extrusion as unconventional SPD process of the ultralow-carbon steel: finite element simulation, experimental investigations and microstructure analysis. Arch Civil Mech Eng. 2021. https://doi. org/10.1007/s43452-020-00166-3.

26. ASTM E8/E8M-13a Standard Test Methods for Tension Testing of Metallic Materials, ASTM International, West Conshohocken. 2013.

27. Ma E. Eight routes to improve the tensile ductility of bulk nanostructured metals and alloys. JOM. 2006;58:49-53.

28. Meyersm MA, Ashworth E. A model for the effect of grain size on the yield stress of metals. Philos Mag A. 1982;46:737-59.

29. Nalepa K, Skoczeń B, Ciepielowska M, et al. Austenitic steel induced by fracture at cryogenic temperatures: experiment and modelling. Materials. 2021;14:127-34.
30. Sun PL, Kao PW, Chang CP. High angle boundary formation by grain subdivision in equal channel angular extrusion. Scripta Mater. 2004;51:565-70.

Publisher's Note Springer Nature remains neutral with regard to jurisdictional claims in published maps and institutional affiliations. 